\title{
Applying catastrophe progression method to evaluate the service quality of cold chain logistics
}

\author{
Hao Zhang ${ }^{1} \cdot$ Yuxin Shi ${ }^{1} \cdot$ Bin Qiu ${ }^{2}$ \\ Received: 8 July 2020 / Accepted: 15 September 2020 \\ (c) The Author(s) 2020
}

\begin{abstract}
Logistics service quality (LSQ) is one of the key influential factors in the success of an ecommerce business. In view of the complexity of the topic, this paper proposes a novel model for fresh ecommerce cold chain LSQ evaluation based on the catastrophe progression method. In the proposed methodology, first an index system for evaluating the fresh ecommerce cold chain LSQ is established from the perspective of service recipients. Then, the comprehensive weight of each evaluation index is determined using a combination weighting approach based on maximizing deviations and fuzzy set theory. The priority weights and the ranking of the indices are determined using the catastrophe progression method. Finally, the model is applied in a case study of two representative enterprises. The study demonstrates the validity and practical applicability of the proposed model. Also, based on the evaluation results and findings, some improvement suggestions are made for improving the cold chain LSQ of similar kinds of fresh ecommerce companies.
\end{abstract}

Keywords Fresh ecommerce $\cdot$ LSQ $\cdot$ Cold chain logistics $\cdot$ Catastrophe progression method · Complexity $\cdot$ Evaluation model

\section{Introduction}

As an industry that recently stood on the cusp of the era of the Internet of Things (IoT) and consumerism, the fresh ecommerce business has gained increasing attention [1-5]. Of all the critical factors that play a role in the production and operation management of a fresh ecommerce business, cold chain logistics has been proved to be the key process that determines its profitability and competitiveness [6, 7]. Since the construction of the cold chain logistics infrastructure network in the fresh ecommerce industry is still nascent, there are problems that business managers cannot ignore. The problems include the lack of coordination within supply

Bin Qiu

qiubin527@163.com

Hao Zhang

zhhaozhhao@126.com

Yuxin Shi

shiyuxin097@163.com

1 School of E-Commerce and Logistics, Beijing Technology and Business University, Beijing 100048,

People's Republic of China

2 State High-Tech Industrial Innovation Center, Shenzhen, People's Republic of China chains, high operational costs, inferior service quality and a relatively low level of customer satisfaction [8-12]. Based on a statistical analysis of the negative comments (1000 samples) posted on fresh ecommerce websites by customers, this paper sorts out the major factors influencing customer satisfaction in order of their importance (Fig. 1) using text mining techniques. From the results, it can be concluded that cold chain LSQ should be taken seriously and improved during the development of the fresh ecommerce industry. Therefore, this paper intends to propose an evaluation method for improving the current cold chain LSQ.

To the best of the knowledge of the authors, there are few studies on the cold chain LSQ evaluation in the fresh ecommerce industry [13, 14]. To fill the research gap, this paper studies the service quality evaluation of cold chain logistics in the fresh ecommerce industry from the perspective of the service recipients (customers). It also establishes an evaluation model that introduces combinatorial weighting into the catastrophe progression method. In addition, an index system for fresh ecommerce cold chain LSQ evaluation is established. The index system is based on the SERVQUAL (short for Service Quality) scale and the LSQ scale. It provides fresh ecommerce businesses with a better understanding of the level of their service quality, and identifies the operational deficiencies that need to be corrected. Overall, this 
Fig. 1 Statistics of the influencing factors of fresh ecommerce cold chain LSQ

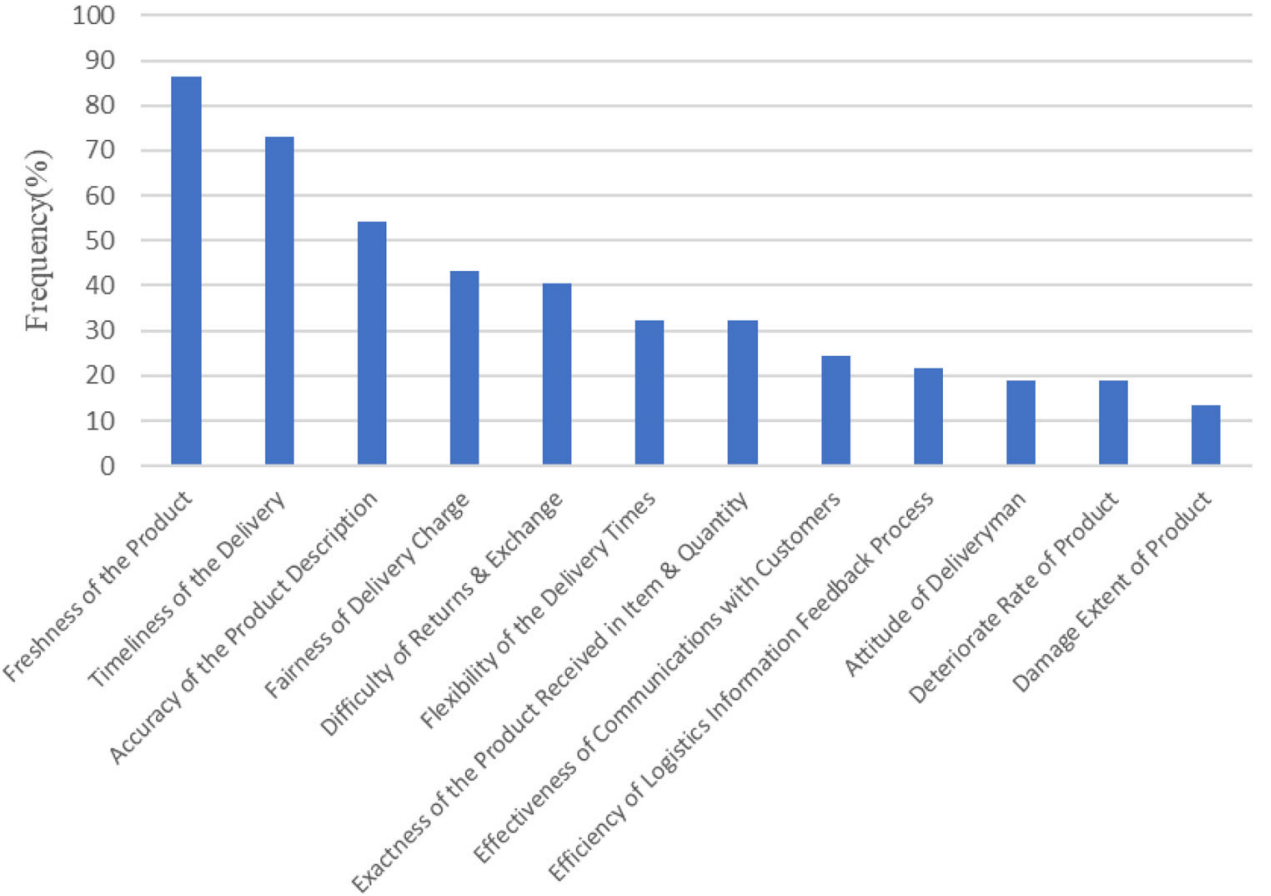

paper presents a new idea for fresh ecommerce businesses to improve their performance and market competitiveness by focusing on the evaluation of cold chain LSQ.

The rest of this paper is organized as follows:

1. Section "Literature review" presents the literature review.

2. Section "Index system of fresh ecommerce cold chain LSQ evaluation" establishes the evaluation index system based on the study of the cold chain distribution of fresh food ecommerce.

3. Section "Evaluation method of fresh ecommerce cold chain LSQ" proposes the evaluation method based on the catastrophe progression method. Section "Empirical study" applies the proposed model in a case study of two representative fresh ecommerce enterprises.

4. Finally, the conclusions are presented in Section "Conclusion".

\section{Literature review}

The existing studies on LSQ are mainly focused on (a) the dimensions and indices of the evaluation model and (b) the techniques that are applied in the comprehensive evaluation of LSQ.

\section{Dimensions and indices of evaluation model}

The LSQ evaluation model has been changing with time, the upgrade of the industrial structure and the definition of LSQ.
The most representative and traditional one is the "7Rs theory", which was proposed by Perreault and Russ (1974). It theorizes that logistics service can be defined as the ability to provide the right products to the right customer at the right price, the right time, the right place, and in the right way to satisfy their specific needs $[15,16]$. This theory lays the foundation for the LSQ evaluation $[17,18]$. With the advent of third-party logistics (TPL), LSQ began to transit from a simple product-oriented concept to a market-oriented one. Lalonde and Zinszer provide new LSQ definitions from the perspective of suppliers [19]. Mentzer et al. further expand the definition of LSQ from the perspective of customers, and design an evaluation model with 9 dimensional indices that cover physical distribution and customer marketing [20]. They suggest that the customer focused evaluation model of LSQ should be objectively established [21, 22]. Based on the theory of Total Quality Management (TQM) and based on sampling from five companies in three industries (Telephone maintenance, Retail banking and Insurance), Parasuraman et al. propose the SERVQUAL model. The SERVQUAL model includes five dimensions of service quality: tangibility, reliability, assurance, responsiveness and empathy. It also includes 22 indices [23]. Bienstock et al. analyse the advantages and shortcomings of the SERVQUAL model and propose the Physical Distribution Service Quality (PDSQ) model based on three criterias: availability, timeliness and condition [24]. Mentzer et al. improve the original model based on existing research on SERVQUAL and PDSQ, and propose the LSQ model. LSQ includes nine dimensions as shown in LSQ Fig. 2 and 25 indices [25]. 


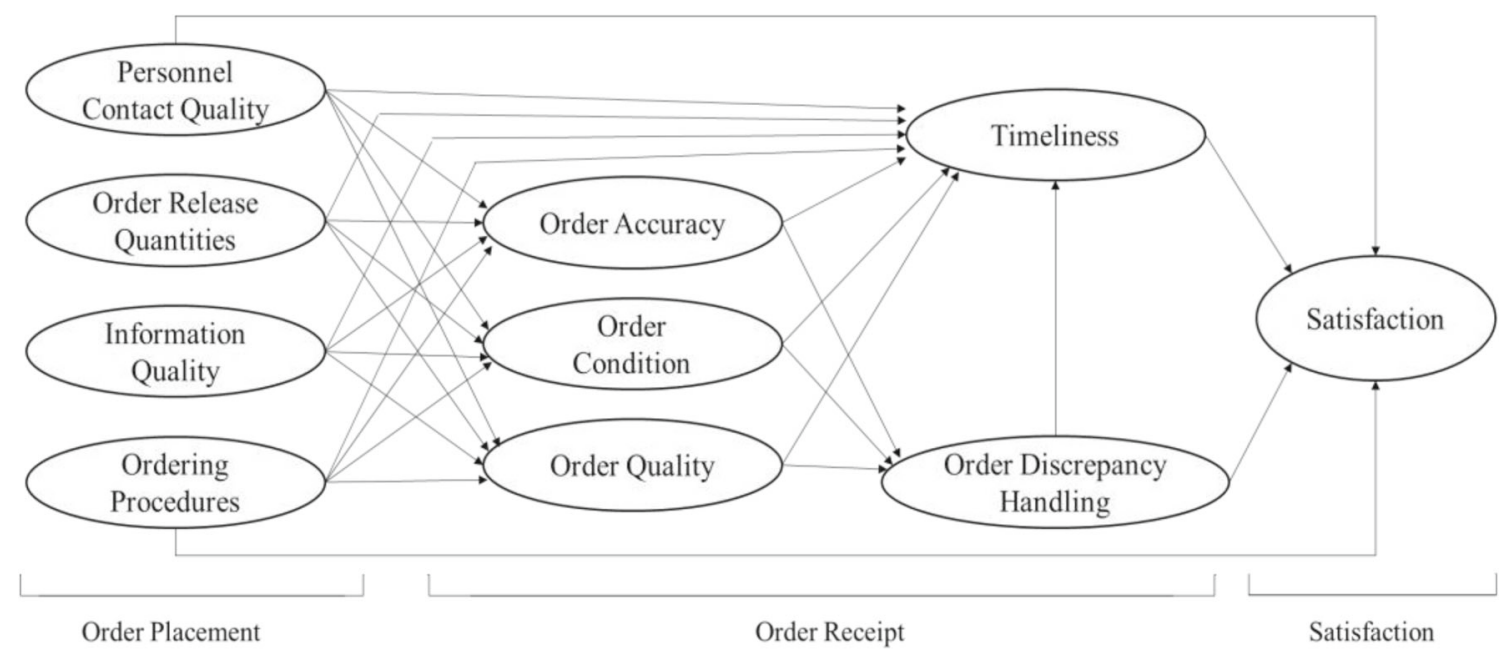

Fig. 2 Dimensions of the LSQ model

After that, endless evaluation models of LSQ emerge. The SERVQUAL model and LSQ model are currently the two most researched ones [26]. Kilibarda et al. develop a modified SERVQUAL model for measuring the LSQ in freight forwarding companies [27]. Gajewska and Grigoroudis apply the integrated SERVQUAL model and ordered weighted averaging technique to evaluate the performance of logistics services in the refrigerated transport industry (from the perspective of refrigerated transport companies) [28]. Hemalatha et al. develop a questionnaire based on the 5 dimensions of the original SERVQUAL model to evaluate the service quality of container terminal operators [29].

From the above, the SERVQUAL model has a limited ability to clearly and objectively explain the correlation among the overall influencing factors, and the LSQ model mainly addresses the relationship between LSQ and suppliers with customer-related variables being less involved [30]. Both the SERVQUAL and LSQ models cannot be universally applied to evaluate the LSQ for enterprises from all industries [31].

\section{Techniques applied in comprehensive evaluation}

There are many techniques that are widely applied in comprehensive evaluations. For example, Wilson et al. adopt the principal component analysis (PCA) technique to assess the retail service quality in farm supply cooperatives [32]. Wei et al. propose an improved fuzzy comprehensive evaluation (FCE) for evaluating hotel service quality [33]. Mahtani and Garg apply a fuzzy analytic hierarchy processing (AHP) technique to identify and rank the key factors [34]. Tuan adopts the structural equation modelling for data analysis for Vietnamese manufacturing firms [35]. As shown in Table 1, this paper compares six dimensions of the commonly used techniques in which each evaluation technique receives a score from 1 to 5 based on their performance ( 1 represents the minimum level).

In summary, all these models have limitations such as the lack of objectivity and high computational complexity $[44,45]$. However, the catastrophe progression method that is applied in this paper has high reliability and objectivity [46]. This technique is derived from change in the state of a nonlinear system, and is very easy to understand and operate. Since it considers the relative importance of evaluation indices instead of merely weighting them, the subjectivity is significantly reduced [47].

Therefore, this paper fills the research gap in determining the evaluation indices of fresh ecommerce cold chain logistics service quality based on SERVQUAL and LSQ. It also establishes the fresh ecommerce cold chain LSQ evaluation model using an improved catastrophe progression method.

\section{Index system of fresh ecommerce cold chain LSQ evaluation}

A sound index system lays a strong foundation for an accurate evaluation of fresh ecommerce cold chain LSQ. Therefore, this paper establishes an evaluation index system with five basic requirements: it must be customer-oriented, systematic, hierarchical, scientific and operable. This process can be divided into two major steps:

1. Establish the evaluation index system based on the SERVQUAL and LSQ models.

2. Amend the initial evaluation index system based on a pilot study. 
Table 1 Comparison results of the commonly used evaluation techniques

\begin{tabular}{|c|c|c|c|c|c|c|c|}
\hline $\begin{array}{l}\text { Evaluation } \\
\text { techniques }\end{array}$ & Required data scale & Reliability & Objectivity & $\begin{array}{l}\text { Computational } \\
\text { complexity }\end{array}$ & Readability & $\begin{array}{l}\text { Implementation } \\
\text { difficulty }\end{array}$ & Related studies \\
\hline $\begin{array}{l}\text { Principal } \\
\text { Component } \\
\text { Analysis (PCA) }\end{array}$ & 3 & 3 & 4 & 3 & 3 & 3 & {$[20,36]$} \\
\hline $\begin{array}{l}\text { Artificial Neural } \\
\text { Network (ANN) }\end{array}$ & 4 & 4 & 5 & 5 & 2 & 5 & {$[37]$} \\
\hline $\begin{array}{l}\text { Fuzzy } \\
\text { Comprehensive } \\
\text { Evaluation } \\
\text { (FCE) }\end{array}$ & 3 & 2 & 2 & 3 & 4 & 3 & {$[38,39]$} \\
\hline $\begin{array}{l}\text { Analytic Hierarchy } \\
\text { Processing } \\
\text { (AHP) }\end{array}$ & 2 & 2 & 1 & 3 & 4 & 4 & [29] \\
\hline $\begin{array}{l}\text { Data Envelopment } \\
\text { Analysis (DEA) }\end{array}$ & 3 & 4 & 4 & 3 & 3 & 5 & {$[40,41]$} \\
\hline $\begin{array}{l}\text { Catastrophe } \\
\text { Progression } \\
\text { Method }\end{array}$ & 3 & 4 & 5 & 2 & 3 & 3 & {$[3,42-43]$} \\
\hline
\end{tabular}

\section{Establishment of initial evaluation index system}

To determine the dimensions of the evaluation index system, this paper systematically studies the cold chain logistics service provided by fresh ecommerce businesses. Then, it modifies, adds, deletes and redefines the five dimensions of the SERVQUAL model based on the influencing factors of fresh ecommerce cold chain LSQ:

- Incorporating Assurance into Reliability.

- Changing Empathy into Accessibility.

- Changing Tangibility into Flexibility.

- Responsiveness remains the same.

- Adding Economy.

The detailed explanations of the five dimensions of the index system of fresh ecommerce cold chain LSQ evaluation are described below.

Reliability represents the ability of fresh ecommerce enterprises to fulfil their commitments and provide the service that they promise to their customers in a reasonable way. In the fresh ecommerce industry, the service that customers receive is determined by the combined effect of the previous assurance from staff (such as delivery men) and the previous reliability from enterprises.

Responsiveness represents the willingness of fresh ecommerce enterprises to help customers and to provide prompt service.

Accessibility represents the ability of fresh ecommerce enterprises to provide their customers with caring, individualized attention, a comprehensive transportation network, flexible delivery schedules, and other additional services that offer great convenience.

Economy represents the service costs that customers need to pay.

Flexibility represents the ability of fresh ecommerce enterprises to maintain their brand image by adopting improvements such as modern facilities, certified products and efficient staff while paying more attention to the customer experience. Customers of fresh ecommerce businesses tend to form their perceptions of the service quality in the communication process. Therefore, tangibility is unable to cover important factors such as the comprehensive qualities of staff.

After the dimensions of the index system of the fresh ecommerce cold chain LSQ evaluation have been determined, this paper proposes 19 indices of the initial evaluation index system. These indices are based on a customer survey, the LSQ model and the requirements and ability of the evaluation indicator of cold chain services for logistics enterprises (GB/T 31086-2014). Table 2 presents an overview of the initial evaluation index system, including the description of each index.

\section{Pilot Study}

\section{Developing the questionnaire}

A questionnaire was designed based on the indices that were identified in Table 2. The questionnaire survey was conducted using a combination of paper and pencil questionnaires and the same version in electronic format. The participants were randomly identified and selected from a combination of peo- 
Table 2 Descriptions of the evaluation indices

\begin{tabular}{ll}
\hline Dimension & Index \\
\hline $\begin{array}{l}\text { Reliability } \\
V_{1}\end{array}$ & Freshness of the product \\
$V_{2}$ & Timely delivery \\
$V_{3}$ & Exactness of the product received in terms of the \\
$V_{4}$ & item type and quantity \\
$V_{5}$ & Damage rate of the product
\end{tabular}

\section{Responsiveness}

$V_{6}$

$V_{7}$

$V_{8}$

$V_{9}$

Accessibility

$V_{10}$

$V_{11}$

$V_{12}$

$V_{13}$

Economy

$V_{14}$

Distribution costs

$V_{15}$

Return costs

Flexibility

$V_{16}$

$V_{17}$

$V_{18}$

$V_{19}$ updates
Efficiency of the order response

Difficulty of returns and exchanges

Efficiency of real-time delivery information

Effectiveness of communications with customers

Coverage rate of the distribution network

Flexibility of the delivery mode

Flexibility of the delivery times

Completeness of the logistics information system

Comprehensive quality of the delivery men

Contact quality of the customer service personnel

Quality of the after-sale service

Efficiency of the feedback system
Description

Whether or not the quality of products can be guaranteed in cold chain logistics

Whether or not orders can be delivered at the designated location when promised

Whether or not orders can be delivered with the correct number of the right items and no substitutions

Whether or not orders get damaged during the cold chain delivery process

Whether or not the information and images of the product in ads are available, are of adequate quality and match reality

Whether or not orders can be handled in a timely manner by fresh ecommerce enterprises

Whether or not the requests for returns and exchanges can be handled in a timely manner by fresh ecommerce enterprises

Whether or not customers can be promptly informed when the logistics information changes

Whether or not customer service personnel can respond to customers promptly

Coverage density of the terminal distribution centre of fresh ecommerce enterprises

Whether or not fresh ecommerce enterprises can provide delivery in the way that their customers prefer

Whether or not fresh ecommerce enterprises can provide deliveries within the time windows that their customers prefer

Whether or not the logistics information system of fresh ecommerce enterprises is equipped with enough referential information for customers

Costs of the cold chain logistics service for customers

Costs incurred when orders delivered do not correspond to what the customers want

Whether or not delivery men are neatly dressed, skilled and have good attitudes

Whether or not the customer service personnel are knowledgeable and empathize with customers' situations, and help them resolve their problems

Whether or not remedial solutions are offered in a timely manner to customers when aftersale problems occur

Whether or not there are effective ways for customers to give feedback 
Table 3 Results of Cronbach's reliability test on each dimension

\begin{tabular}{llll}
\hline Dimension & $\begin{array}{l}\text { Cronbach's } \\
\text { alpha }\end{array}$ & $\begin{array}{l}\text { Cronbach's } \\
\text { alpha for the } \\
\text { standardized } \\
\text { items }\end{array}$ & $\begin{array}{l}\text { Number of } \\
\text { items }\end{array}$ \\
\hline Reliability & 0.718 & 0.724 & 5 \\
Responsiveness & 0.659 & 0.665 & 4 \\
Accessibility & 0.637 & 0.638 & 4 \\
Economy & 0.631 & 0.632 & 2 \\
Flexibility & 0.637 & 0.659 & 4 \\
\hline
\end{tabular}

ple who experienced fresh ecommerce shopping, people who have a willingness to place fresh ecommerce orders, and staff who work in the fresh-ecommerce industry. To ensure that the questionnaire is as concise and precise as possible, a five-point Likert-type scale from 'unimportant' to 'very important' was applied to investigate the individual responses on the service quality of cold chain logistics in the fresh ecommerce industry. A three-point Likert-type scale from 'not satisfied' to 'very satisfied' was used for the fresh ecommerce customers to rate their satisfaction level.

\section{Collecting the data}

219 questionnaires were distributed, including 158 in electronic form and 61 in paper form. A total of 210 of them were answered, resulting in a response rate of $95.89 \%$. Then, 205 of the questionnaires are valid, resulting in an effective response rate of $97.6 \%$. Overall, 147 respondents were customers who experienced fresh ecommerce shopping, and 72 respondents were potential customers of fresh ecommerce.

\section{Reliability analysis of the questionnaire}

To assess the reliability of the collected samples, this paper uses Cronbach's alpha, which is calculated using SPSS 21.0. The overall Cronbach's alpha for the questionnaire is 0.871 , which means that the questionnaire has high reliability.

\section{Correlation analysis}

To improve the rationality of the index system for the fresh ecommerce cold chain LSQ evaluation, this paper further examines the correlation between the indices and analyses the items that have weak correlations with the system. As shown in Table 3, this paper calculates the Cronbach's alpha for each dimension of the evaluation index system. Table 4 presents the overall correlation coefficient of each index under the dimension it belongs to.
Based on the data provided in Tables 4 and 5, indices were removed from the initial index system of the fresh ecommerce cold chain LSQ evaluation for two reasons:

1. a total correlation lower than 0.4 ,

2. deleting the index will improve the overall Cronbach's alpha of that dimension (refers to 'Cronbach's Alpha if Item Deleted').

These items are $V_{13}$ 'Accessibility' and $V_{19}$ 'Flexibility'. It is not difficult to find that these two indices are more related to the perspective of service providers than that of service recipients.

According to the above analysis results, the final index system for evaluating the fresh ecommerce cold chain LSQ includes five dimensions and 17 indices. As illustrated in Fig. 3, the indices are re-numbered for narrative convenience.

\section{Evaluation method of fresh ecommerce cold chain LSQ}

\section{Standardization of data}

The raw data of each index needs to be standardized to a dimensionless value between 0 and 1 before the following steps. There are two types of indices in the index system of the fresh ecommerce cold chain LSQ evaluation: benefit type indices and cost type indices. To eliminate the discrepancy among the raw data of each index in each dimension, the standardization is performed based on the principle that the larger the number is, the better the performance. Let $U=\left\{u_{1}, u_{2}, \ldots, u_{n}\right\}$ denote the set of $n$ respondents to the fresh ecommerce cold chain LSQ evaluation, and let $N=\{1,2, \ldots, n\}$. Let $V=\left\{v_{1}, v_{2}, \ldots, v_{m}\right\}$ denote the set of $m$ indices that are to be evaluated in the evaluation index system, and let $M=\{1,2, \ldots, m\}$.

The formula for standardizing the positive indices or benefit type indices is

$z_{i j}=\frac{p_{i j}-p_{\min }(j)}{p_{\max }(j)-p_{\min }(j)}, i \in N, j \in M$,

and the formula for standardizing negative indices or cost type indices is

$z_{i j}=\frac{p_{\max }(j)-p_{i j}}{p_{\max }(j)-p_{\min }(j)}, i \in N, j \in M$,

where $z_{i j}$ is the standardized evaluation score of the $j$ th index that belongs to the $i$ th respondent, $p_{i j}$ represents the original data, and $p_{\max }(j)$ and $p_{\min }(j)$ represent the maximum and minimum evaluation scores of the $j$ th index for all respondents, respectively. 
Table 4 Overall correlation coefficient of each index under a certain dimension

\begin{tabular}{llllll}
\hline Item & $\begin{array}{l}\text { Scale mean if } \\
\text { item deleted }\end{array}$ & $\begin{array}{l}\text { Scale variance if } \\
\text { item deleted }\end{array}$ & $\begin{array}{l}\text { Corrected item } \\
\text { total correlation }\end{array}$ & $\begin{array}{l}\text { Squared multiple } \\
\text { correlation }\end{array}$ & $\begin{array}{l}\text { Cronbach's } \\
\text { alpha if item } \\
\text { deleted }\end{array}$ \\
\hline$V_{1}$ & 17.4390 & 3.757 & 0.382 & 0.191 & 0.708 \\
$V_{2}$ & 17.8195 & 3.109 & 0.484 & 0.300 & 0.667 \\
$V_{3}$ & 17.8537 & 3.018 & 0.563 & 0.336 & 0.637 \\
$V_{4}$ & 17.9902 & 2.853 & 0.488 & 0.299 & 0.667 \\
$V_{5}$ & 18.0878 & 2.728 & 0.506 & 0.294 & 0.662 \\
$V_{6}$ & 12.5707 & 3.325 & 0.445 & 0.230 & 0.592 \\
$V_{7}$ & 12.6293 & 2.685 & 0.455 & 0.219 & 0.589 \\
$V_{8}$ & 12.5805 & 3.058 & 0.440 & 0.205 & 0.591 \\
$V_{9}$ & 12.4878 & 3.310 & 0.438 & 0.226 & 0.595 \\
$V_{10}$ & 12.1610 & 3.283 & 0.381 & 0.150 & 0.595 \\
$V_{11}$ & 12.2829 & 3.145 & 0.485 & 0.382 & 0.519 \\
$V_{12}$ & 12.3171 & 3.071 & 0.527 & 0.399 & 0.488 \\
$V_{13}$ & 12.5854 & 3.665 & 0.289 & 0.100 & 0.654 \\
$V_{14}$ & 4.1220 & 0.666 & 0.462 & 0.213 & - \\
$V_{15}$ & 4.2244 & 0.596 & 0.462 & 0.213 & - \\
$V_{16}$ & 11.9171 & 3.449 & 0.472 & 0.287 & 0.528 \\
$V_{17}$ & 11.7463 & 3.749 & 0.480 & 0.321 & 0.534 \\
$V_{18}$ & 11.6829 & 3.737 & 0.463 & 0.229 & 0.543 \\
$V_{19}$ & 12.3902 & 3.386 & 0.307 & 0.112 & \\
\hline & & & & & 0.676 \\
\hline
\end{tabular}

Table 5 Common catastrophe models

\begin{tabular}{lll}
\hline Type & Number of control variables & Potential function \\
\hline Cusp model & 2 & $f(x)=\frac{1}{4} x^{4}+\frac{1}{2} a x^{2}+b x$ \\
Swallowtail model & 3 & $f(x)=\frac{1}{5} x^{5}+\frac{1}{3} a x^{3}+\frac{1}{2} b x^{2}+c x$ \\
Butterfly model & 4 & $f(x)=\frac{1}{6} x^{6}+\frac{1}{4} a x^{4}+\frac{1}{3} b x^{3}+\frac{1}{2} c x^{2}+d x$ \\
Wigwam model & 5 & $f(x)=\frac{1}{7} x^{7}+\frac{1}{5} a x^{5}+\frac{1}{4} b x^{4}+\frac{1}{3} c x^{3}+\frac{1}{2} d x^{2}+e$ \\
\hline
\end{tabular}

\section{Determination of the importance degree of indices}

The importance of the indices in the evaluation index system are not uniform, and this is reflected in the weight value of each index. In this paper, the index weight is a combination of the variable weight and the attribute weight.

\section{Determination of variable weights}

The basic idea of maximizing deviations is to choose an optimal weight vector out of random numbers based on whether it can obtain the maximum total deviation of the indices of all dimensions. The deviation value embodies the divergence of the respondents' perceptions of a certain index. If the deviation value of an index is bigger, the influence of this index is larger. Therefore, its weight should be set higher. The process of maximizing deviations is as follows:

First, assume that the variable weight vector of $m$ indices in the evaluation index system is $w^{1}=\left(w_{1}^{1}, w_{2}^{1}, \ldots, w_{m}^{1}\right)$, where $w_{j}^{1}$ is the variable weight of the $j$ th index, and it satisfies the constrain that $\sum_{j=1}^{m} w_{j}^{1}=1\left(w_{j} \geq 0, j \in M\right)$. Therefore, the standardized weighted decision matrix $\mathbf{Z}$ can be determined as follows:

$\mathbf{Z}=\left[\begin{array}{ccccccc}w_{1}^{1} z_{11} & w_{2}^{1} & z_{12} & \cdots & w_{m}^{1} & z_{1 m} \\ w_{1}^{1} & z_{21} & w_{2}^{1} & z_{22} & \cdots & w_{m}^{1} & z_{2 m} \\ \vdots & \multicolumn{2}{c}{} & \vdots & & \vdots \\ w_{1}^{1} & z_{n 1} & w_{2}^{1} & z_{n 2} & \cdots & w_{m}^{1} & z_{n m}\end{array}\right]$.

Then, this paper defines the deviation between the perceptions of the $i$ th respondent, $u_{i}$, and all the others on the $j$ th index as $d_{i j}$, which is calculated as follows:

$d_{i j}=\sum_{k=1}^{n}\left|z_{i j}-z_{k j}\right| \times w_{j}^{1}$ 


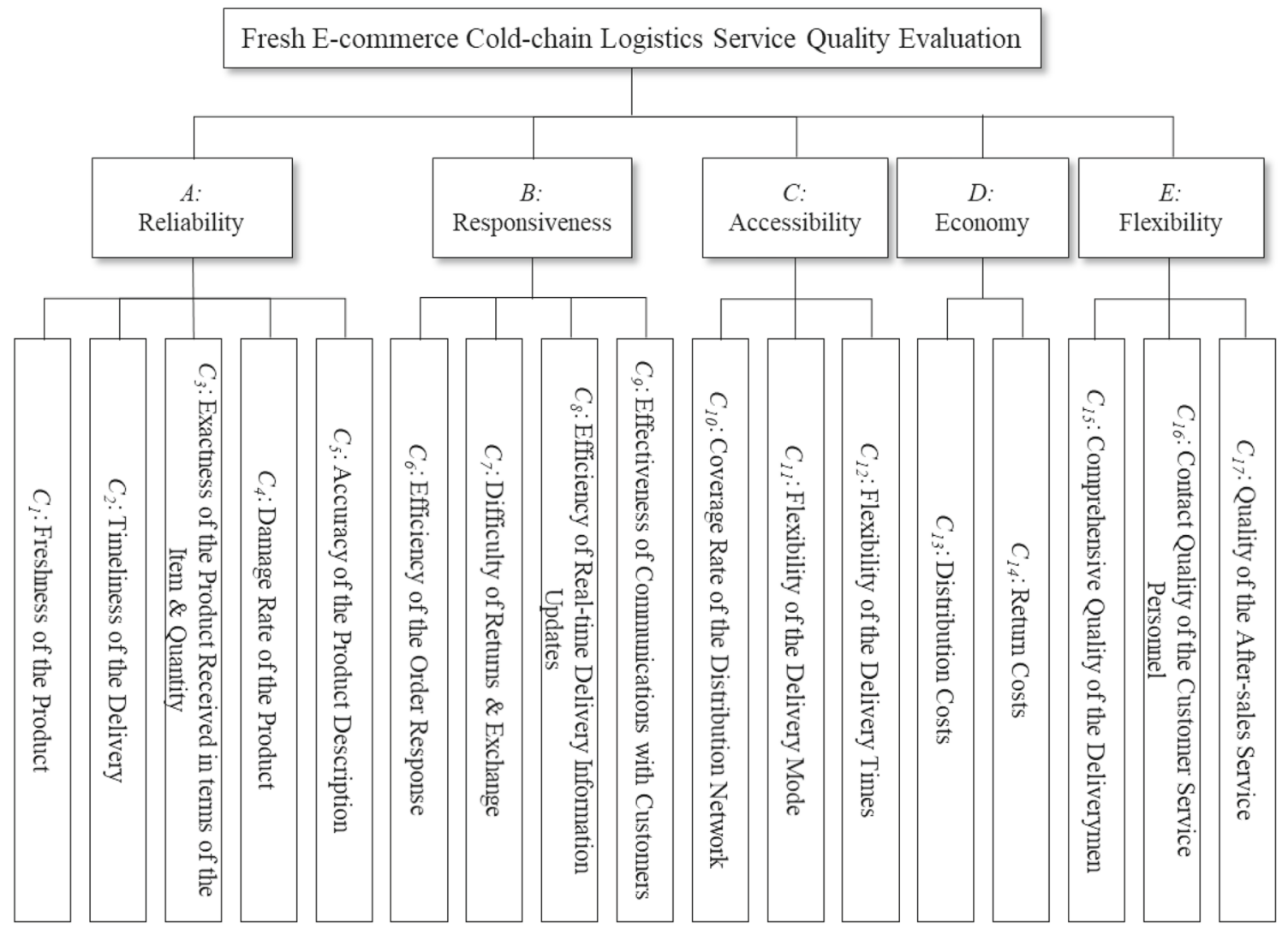

Fig. 3 Index system of the fresh ecommerce cold chain LSQ evaluation

where $i \in N, j \in M$. In the terms of the $j$ th index, the total deviation between all the respondents is defined as $d_{j}$, and it is calculated as follows:

$d_{j}=\sum_{i=1}^{n} d_{i j}=\sum_{i=1}^{n} \sum_{k=1}^{n}\left|z_{i j}-z_{k j}\right| \times w_{j}^{1}$,

where $j \in M$. Therefore, the total deviation between all the respondents on the overall index system is defined as $D(w)$, and it is calculated as follows:

$D(w)=\sum_{j=1}^{m} d_{j}=\sum_{j=1}^{m} \sum_{i=1}^{n} \sum_{k=1}^{n}\left|z_{i j}-z_{k j}\right| \times w_{j}^{1}$.

Based on the above analysis, the maximizing deviations model is constructed as follows:

$\left\{\begin{array}{c}\max D(w)=\sum_{j=1}^{m} \sum_{i=1}^{n} \sum_{k=1}^{n}\left|z_{i j}-z_{k j}\right| \cdot w_{j}^{1} \\ \text { s.t. } w_{j} \geq 0, \sum_{j=1}^{m}\left(w_{j}^{1}\right)^{2}=1\end{array}\right.$.
Next, the optimal solution of the above model is obtained by applying the Lagrange method:

$w_{j}^{*}=\frac{\sum_{i=1}^{n} \sum_{k=1}^{n}\left|z_{i j}-z_{k j}\right|}{\sqrt{\sum_{j=1}^{m}\left[\sum_{i=1}^{n} \sum_{k=1}^{n}\left|z_{i j}-z_{k j}\right|\right]^{2}}}$.

Then, the standardized variable weight $w_{j}^{1}$ of the $j$ th index is obtained based on the following formula:

$w_{j}^{1}=\frac{w_{j}^{*}}{\sum_{j=1}^{m} w_{j}^{*}}=\frac{\sum_{i=1}^{n} \sum_{k=1}^{n}\left|z_{i j}-z_{k j}\right|}{\sum_{j=1}^{m} \sum_{i=1}^{n} \sum_{k=1}^{n}\left|z_{i j}-z_{k j}\right|}$.

\section{Determination of attribute weights}

The variable weights of the indices in the fresh ecommerce cold chain LSQ evaluation can be easily modified due to the influence of subjective factors. Therefore, this paper further considers the attribute weights in the determination of the index weight using rough set theory. The basic idea of rough set theory is to determine the importance of each attribute depending on the approximate quality of the classification 
reduction [48, 49]. The calculation process is presented below.

First, assuming there is a fuzzy information system IS = $\{U, A\}$, where $U$ and $A$ are nonempty finite and denote the universe of the data from the questionnaire and the set of attributes, respectively. $A=C \cup D$ and $C \cap D=\emptyset$, where $C=\left\{C_{j} \mid j=1,2, \cdots, m\right\}$ is the set of conditional attributes, where $C_{j}$ denotes the set of a customer's perceived value of $j$ th index in the evaluation index system, and $D$ is the set of decision-making attributes, which include the customer's perception of their overall satisfaction with the fresh e-commerce cold-chain logistics service quality.

Second, assuming there is a decision-making table DS = $\left\{U, A, V_{\mathrm{a}}, f, d\right\}$, where every attribute $a \in A$, there are two information functions, which are denoted as $f$ and $d$ :

$$
\begin{aligned}
& f: U \times C \rightarrow V_{\mathrm{a}}, \\
& d: U \times D \rightarrow V_{\mathrm{a}}
\end{aligned}
$$

where $V_{a}$ is the value of $a$. Let $U / C$ denote the sets of equivalence classes that classify the attributes of $C$ in different ways. Then, the positive region relative to $D$ in $C$ is defined as $\operatorname{POS}_{C}(D)$. Let IND $(P)$ denote the subset $P$ of $C$ that determines an indiscernibility relation on $U$, and it is represented as

$\operatorname{IND}(P)=\{(x, y) \in U \times U \mid \forall p \in P, f(x, p)=f(y, p)\}$.

Accordingly, the equivalence class of $\operatorname{IND}(P)$ is denoted as $U / \operatorname{IND}(P)$.

Third, we calculate the importance degree for attribute $C_{j} \in C$ relative to $D$. The formula is as follows:

$$
w_{j}^{\prime}=\gamma_{C}(D)-\gamma_{C-C_{j}}(D)=\frac{\left|\operatorname{POS}_{C}(D)\right|-\left|\operatorname{POS}_{C-C_{j}}(D)\right|}{|U|},
$$

where $\gamma_{C}(D)$ represents the quality of the classification by $C$ relative to $D$, and $\gamma_{C-C_{j}}(D)$ describes the quality of the classification that removes the attribute subset $C_{j}$ in $C$ relative to $D$.

Finally, the standardized attribute weights of the indices in the evaluation index system are calculated based on the following formula:

$$
w_{j}^{2}=\frac{w_{j}^{\prime}}{\sum_{j=1}^{m} w_{j}^{\prime}} .
$$

\section{Determination of comprehensive weights}

To determine the comprehensive weights of the indices in the evaluation index system and rank them in order of importance, the following formula is applied:

$\delta_{j}=\alpha_{1} \times w_{j}^{1}+\alpha_{2} \times w_{j}^{2}, j \in M$

where $\delta_{j}$ is the comprehensive weight of the $j$ th index, and $w_{j}^{1}$ and $w_{j}^{2}$ represent the variable weight and attribute weight of the $j$ th index, respectively. $\alpha_{1}$ and $\alpha_{2}$ are coefficients, and they are calculated as follows:

$$
\left\{\begin{array}{c}
\min \sum_{j=1}^{m} \sum_{k=1}^{2} \sum_{i=1}^{2}\left(\alpha_{k} w_{j}^{k}-\alpha_{i} w_{j}^{i}\right)^{2} / 2 \\
\text { s.t. } \alpha_{k} \geq 0, \alpha_{1}+\alpha_{2}=1
\end{array} .\right.
$$

Similarly, the weights of the dimensions are calculated in the same way.

\section{Establishment of catastrophe evaluation model}

Since the number and weights of the dimensions and indices are determined in the previous steps, a corresponding catastrophe evaluation model of fresh ecommerce cold chain LSQ is established using the requirements of the catastrophe progression method:

- determining the catastrophe types at each level of the index system based on the number of sub-indices, and,

- Ranking the indices based on their relative importance.

According to the catastrophe theory, there are two kinds of variables in the catastrophe system: the state variables that reflect the behavioural state of the system, and the control variables that influence the behavioural state. As shown in Table 6, the four types of common catastrophe models are divided by the number of control variables (sub-indices) that they include. $f(x)$ is the potential function of the state variable $x$, and $a, b, c, d$ and $e$ are the control variables of the state variable, which have different influences on $x$.

The evaluation index system of fresh ecommerce cold chain LSQ has five dimensions: Reliability (5 subindices), Responsiveness (4 sub-indices), Accessibility (3 sub-indices), Economy ( 2 sub-indices) and Flexibility (3 subindices). According to the number of control variables in each dimension and each level, the corresponding catastrophe evaluation model of fresh ecommerce cold chain LSQ is obtained. Dimensions and indices of each dimension are ordered in sequence according to their variable weights. 


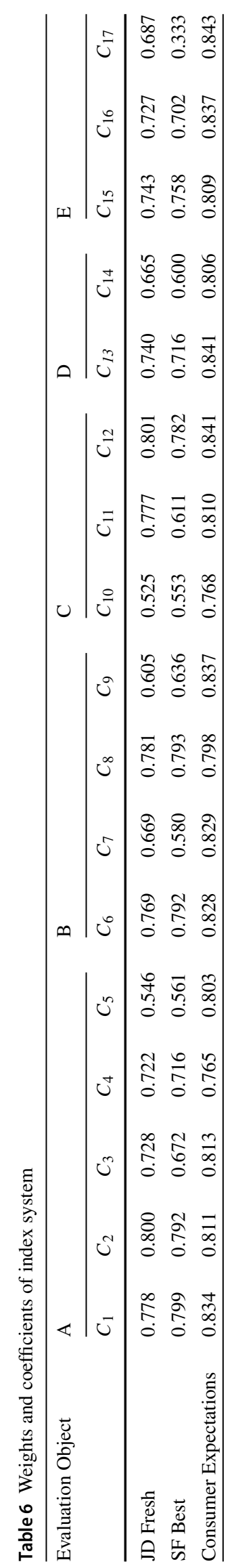

\section{Evaluation of the catastrophe progression value}

In catastrophe theory, an equilibrium surface is formed using the critical points of the potential function $f(x)$. By setting $f^{\prime}(x)=0$, the equation of that surface is obtained and eventually, by eliminating $x$ between $f^{\prime}(x)=0$ and $f^{\prime \prime}(x)=0$, the equation of the set of bifurcation points is obtained. Then the standardization formula is derived from the decomposed forms of the bifurcation equation, and is adopted to calculate the catastrophe membership function value of each state variable according to its control variables. The standardization formulas of the four common catastrophe models presented in Table 6 are as follows:

Cusp model : $x_{\mathrm{a}}=a^{1 / 2}, x_{\mathrm{b}}=b^{1 / 3}$

Swallowtail model : $x_{\mathrm{a}}=a^{1 / 2}, x_{\mathrm{b}}=b^{1 / 3}, x_{\mathrm{c}}=c^{1 / 4}$

Butterfly model : $x_{\mathrm{a}}=a^{1 / 2}, x_{\mathrm{b}}=b^{1 / 3}, x_{\mathrm{c}}=c^{1 / 4}$

Wigwam model : $x_{\mathrm{a}}=a^{1 / 2}, x_{\mathrm{b}}=b^{1 / 3}$,

$$
x_{\mathrm{c}}=c^{1 / 4}, x_{\mathrm{d}}=d^{1 / 5}, x_{\mathrm{e}}=e^{1 / 6} \text {. }
$$

Taking the cusp model as an example, $x_{\mathrm{a}}$ and $x_{\mathrm{b}}$ are the values of $x$ corresponding to a and $\mathrm{b}$, respectively, and control variable a always has more influence in $x$ than $\mathrm{b}$. After obtaining the standardized value of the state variables in view of each control variable, the catastrophe membership function values are calculated based on the following principles: the complementary and the non-complementary principles. The basic idea of the non-complementary principle is that if there is no obvious correlation between a set of noncomplementary control variables, the membership function of the state variable is the minimum value among its control variables, i.e., $x=\min \left\{x_{\mathrm{a}}, x_{\mathrm{b}}\right\}$. If there is an obvious correlation between the control variables, the complementary principle is adopted, which implies that the membership function of the state variable depends on the average value of its control variables, i.e., $x=\left(x_{\mathrm{a}}+x_{\mathrm{b}}\right) / 2$. We use SPSS 21.0 to calculate the correlation coefficient between the control variables, and reach a decision on whether to use the noncomplementary or complementary principle based on the results.

The evaluation of the catastrophe progression value is performed from the bottom layer in the index system of the fresh ecommerce cold chain LSQ and up. Finally, the comprehensive catastrophe membership value is obtained. 
Table 7 Weights and coefficients of the index system

\begin{tabular}{llll}
\hline Dimension & $\begin{array}{l}\text { Variable weight } \\
\text { of dimension }\end{array}$ & Index & $\begin{array}{l}\text { Variable weight } \\
\text { of index }\end{array}$ \\
\hline Reliability & 0.302 & $C_{1}$ & 0.210 \\
& & $C_{2}$ & 0.211 \\
& & $C_{3}$ & 0.188 \\
& & $C_{4}$ & 0.206 \\
Responsiveness & 0.237 & $C_{5}$ & 0.186 \\
& & $C_{6}$ & 0.263 \\
Accessibility & 0.171 & $C_{7}$ & 0.254 \\
& & $C_{8}$ & 0.260 \\
Economy & \multirow{2}{*}{0.118} & $C_{9}$ & 0.222 \\
& & $C_{10}$ & 0.234 \\
Flexibility & \multirow{2}{*}{0.172} & $C_{11}$ & 0.234 \\
& & $C_{12}$ & 0.234 \\
& & $C_{13}$ & 0.521 \\
& & $C_{14}$ & 0.479 \\
& & $C_{15}$ & 0.356 \\
& & $C_{16}$ & 0.333 \\
& & $C_{17}$ & 0.331 \\
\hline
\end{tabular}

\section{Empirical study}

\section{Data collection and sample analysis}

This paper conducted a questionnaire survey with the customers of JD Fresh and SF Best, which are two representative fresh ecommerce enterprises, to investigate the cold chain LSQ. According to the index system of the fresh ecommerce cold chain LSQ evaluation that is proposed in this paper, a questionnaire was developed from two perspectives: the consumers' expectations before sales and their satisfaction after sales. The consumer expectation is evaluated using a fivepoint Likert-type scale, with 5 being 'Strongly Agree' and 1 being 'Strong disagree'. The customer satisfaction is evaluated using the same Likert-type scale, with 5 being 'Strongly Satisfied' and 1 being 'Strongly Dissatisfied'.

The main distribution methods for the questionnaires were as follows:

1. Sharing the questionnaires in electronic form with potential respondents on social media, such as Facebook, WeChat, BBS, and Email.

2. Handing out the questionnaires in paper form to potential respondents who pick up their orders around self-service lockers.

Subsequently, 198 questionnaire responses were gathered including 111 in electronic form and 87 in paper form. 185 of them are valid and can be used for the analysis, resulting in an effective response rate of $93.4 \%$. Overall, among all the valid answer sheets, 119 respondents were people who only experienced fresh ecommerce shopping on JD Fresh, 32 respondents were people who only experienced fresh ecommerce shopping on SF Best, and the rest of them were customers of both enterprises. The effective response rates for these three groups were $95.20 \%, 91.43 \%$ and $89.47 \%$, respectively.

The Cronbach's alpha test that was conducted through SPSS 21.0 resulted in a value of 0.851 , which means the questionnaire has a high level of validity. The KMO index is 0.795 , and the Bartlett test is $1395.944(d f=136)$ with a significance of 0.000 . This shows that the correlation between the indices is relatively strong and that the sample is adequate for factor analysis. Then, exploratory factor analysis was performed on the collected valid sample. The analysis indicates that there are five factors with eigenvalues above 1 in the seventeen indices, thus accounting for $64.55 \%$ of the total variance. The factor loadings of each index range from 0.477 to 0.729 , and only one of them is below 0.5 . The exploratory factor analysis further proves the construct validity of the developed questionnaire.

\section{Service quality evaluation for JD fresh and SF best}

Based on the technique of data standardization, the raw data that were collected from the questionnaires were standardized and are listed in Table 6.

According to the evaluation method that was developed in this paper, the variable weights of the dimensions and the indices of each dimension were obtained and are presented in Table 7.

Based on the above variable weight, the coefficients $\alpha_{1}$ and $\alpha_{2}$ are calculated according to formula (12). With respect to the variables in every level and all the dimensions, the values of $\alpha_{1}$ and $\alpha_{2}$ are 0.35 and 0.65 , respectively. Then, the comprehensive weights of the dimensions and indices of each dimension are obtained according to formula (11). Accordingly, the type of catastrophe model for each state variable is determined. Therefore, as shown in Fig. 4, the corresponding catastrophe evaluation model of fresh ecommerce cold chain LSQ is established. The dimensions are ranked in descending order by their importance from left to right, and the indices below them are ranked in the same order from top to bottom.

Based on the type of catastrophe model between each state variable and their control variables, the standardization formulas are determined accordingly. The decisions on which principle should be used in the determination of the catastrophe membership function value for each state variable are also reached according to the following. The complementary principle will be adopted only under the condition that all control variables have a correlation coefficient above

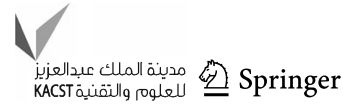




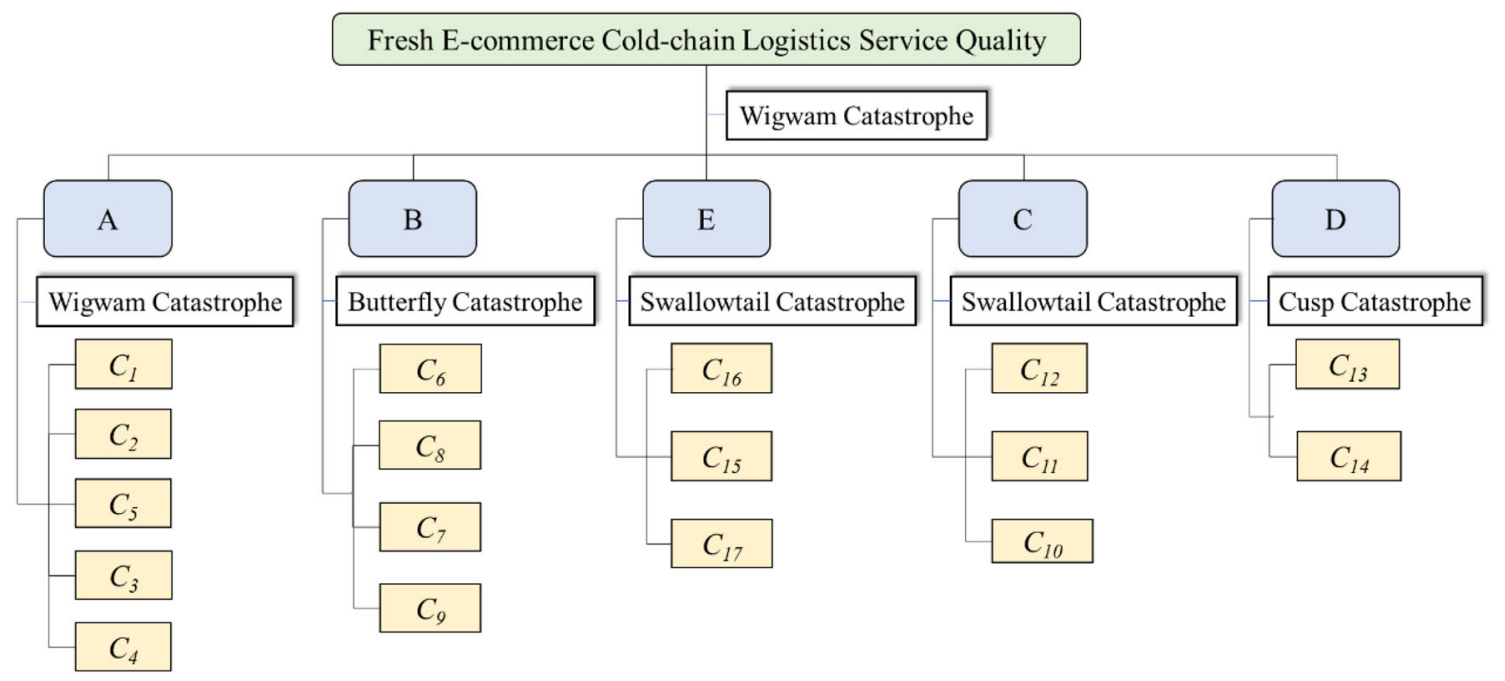

Fig. 4 Catastrophe evaluation model of fresh ecommerce cold chain LSQ

Fig. 5 Surface chart of the evaluation results

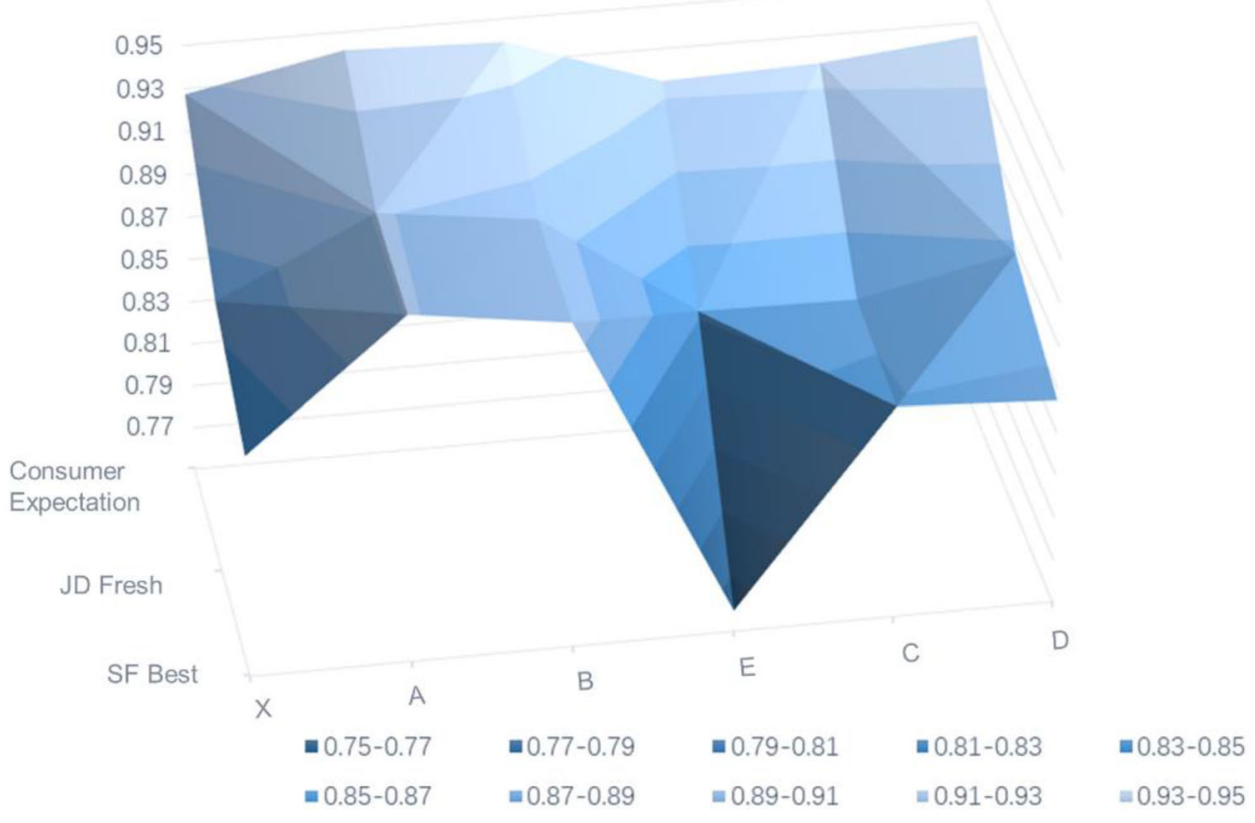

0.4. Otherwise, the non-complementary principle will be adopted.

Therefore, according to the correlation coefficients of the indices in Table 6, the complementary principle will be adopted for 'Reliability' and 'Economy', and the noncomplementary principle will be adopted for 'Responsiveness', 'Accessibility' and 'Flexibility'. In addition, when serving as control variables, the overall correlation coefficients of the five dimensions are 0.501 ('Reliability'), 0.820 ('Responsiveness'), 0.578 ('Flexibility'), 0.693 ('Accessibility') and 0.787 ('Economy'). It shows a relatively strong correlation among the dimensions. Accordingly, the complementary principle will also be adopted in the calculation of the overall catastrophe membership function values.
The catastrophe membership function values are obtained, which can also be seen as the results of the fresh cold chain LSQ evaluation for JD Fresh and SF Best. A surface chart is also presented in Fig. 5 to illustrate the results in an intuitive way.

\section{Analysis of results}

By comparing the evaluation results for the fresh cold chain LSQ of JD Fresh and SF Best based on consumer expectations, the conclusions are drawn and presented as follows.

According to the results of the comprehensive evaluation, the cold chain logistics service of both JD Fresh and SF Best are proved to operate at a relatively high level (both 
exceed 0.85). However, when compared with the service quality that consumers expected (0.923), it reveals that there is still plenty of room for improvement. Overall, the service quality of JD Fresh (0.8767) is higher than that of SF Best (0.8529). The superiority of JD Fresh over SF Best is mainly embodied in its 'Service Flexibility' (0.8525) and 'Economy' (0.8665). For the other dimensions in the index system, the evaluation scores of the two fresh enterprises are similar. However, 'Service Flexibility', 'Accessibility' and 'Economy' are the three critical factors that may hinder the development of the cold chain LSQ These three factors should be paid special attention in both fresh ecommerce enterprises. In the view of the indices in the evaluation index system, both JD Fresh and SF Best demonstrate relatively high service quality with respect to 'Timeliness of Delivery' $\left(C_{1}\right)$, 'Exactness of the Product Received with respect to the Item and Quantity' $\left(C_{3}\right)$, 'Damage Rate of the Product' $\left(C_{4}\right)$, 'Efficiency of Real-time Delivery Information Update' $\left(C_{8}\right)$ and 'Comprehensive Quality of Deliverymen' $\left(C_{16}\right)$, and fail to meet the consumers' expectations in 'Accuracy of the Product Description' $\left(C_{5}\right)$, 'Effectiveness of the Communications with the Customer' $\left(C_{9}\right)$, 'Coverage Rate of the Distribution Network' $\left(C_{10}\right)$ and 'Return Costs' $\left(C_{14}\right)$, which need improvement. In addition, SF Best should focus on solving the problems and issues in 'Difficulty of Returns and Exchanges' $\left(C_{7}\right)$, 'Flexibility of the Delivery Mode' $\left(C_{11}\right)$ and 'Quality of After-sales Service' $\left(C_{17}\right)$.

There are some mutual problems existing in both JD Fresh and SF Best, which are also common in the fresh ecommerce industry. The most important and influential one is the high costs of cold chain logistics. Since JD Fresh and SF Best already have advantages over others in terms of their broad logistics network, it is necessary and urgent to further adjust the structure of the logistics system and optimize the resource allocation decisions. This can improve the efficiency of the costly self-built cold chain logistics. In addition, employee quality is also an important issue that fresh ecommerce enterprises like JD Fresh and SF Best should focus on.

\section{Conclusion}

In summary, this study started with two main objectives:

1. Establishing an index system of the cold chain LSQ evaluation for fresh ecommerce.

2. Proposing an advanced method based on catastrophe progression method for evaluating the service quality in a more objective and accurate way.

Then, according to the study of the index system and the evaluation method, this paper evaluates the cold chain LSQ for two representative enterprises in the fresh ecom- merce industry from the perspective of service recipients (customers). Finally, the validity of the proposed evaluation method is verified.

\section{Foundation}

1. National Key R\&D Program of China (2017YFC1600605),

2. Beijing Philosophy and Social Science (17GLB013),

3. 2018 Beijing Talents foundation of organization department of Beijing Municipal Committee of the CPC (2018000026833ZS09),

4. Science and technology innovation service capacity provincial—ministerial scientific research platform construction social science provincial-ministerial scientific research platform construction project (19008020111).

Acknowledgements The funding was funded by National Key R\&D Program of China (2017YFC1600605), Beijing Philosophy and Social Science (Grant 17GLB013), Natural Science Foundation of Beijing Municipality (CN) (Grant 2018000026833ZS09) and Science and technology innovation service capacity provincial - ministerial scientific research platform construction social science provincial - ministerial scientific research platform construction project (Grant 19008020111).

Open Access This article is licensed under a Creative Commons Attribution 4.0 International License, which permits use, sharing, adaptation, distribution and reproduction in any medium or format, as long as you give appropriate credit to the original author(s) and the source, provide a link to the Creative Commons licence, and indicate if changes were made. The images or other third party material in this article are included in the article's Creative Commons licence, unless indicated otherwise in a credit line to the material. If material is not included in the article's Creative Commons licence and your intended use is not permitted by statutory regulation or exceeds the permitted use, you will need to obtain permission directly from the copyright holder. To view a copy of this licence, visit http://creativecomm ons.org/licenses/by/4.0/.

\section{References}

1. Ruan J, Shi Y (2016) Monitoring and assessing fruit freshness in iot-based e-commerce delivery using scenario analysis and interval number approaches. Inf Sci 373:557-570

2. Zhang S, Zhang W, Zhang L, Qi Q, Huang W (2019) Analysis of water area in caofeidian wetland in 1984-2013 based on remote sensing image data. Environ Eng Manag J 18(6):1347-1355

3. Zhang WW, Xu XH, Chen XH (2017) Social vulnerability assessment of earthquake disaster based on the catastrophe progression method: a Sichuan province case study. Int J Disaster Risk Reduct 24:361-372

4. Zhang H, Cui Y (2019) A model combining a bayesian network with a modified genetic algorithm for green supplier selection. Simul Trans Soc Model Simul Int 95(12):1165-1183

5. Zhang H, Tang L, Yang C, Lan S (2019) Locating electric vehicle charging stations with service capacity using the improved whale optimization algorithm. Adv Eng Inf 41(08)

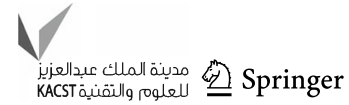


6. Du J, Li Q, Qiao F, Yu L (2018) Estimation of vehicle emission on mainline freeway under isolated and integrated ramp metering strategies. Environ Eng Manag J 17(5):1237-1248

7. Wu JH (2017) Research on operation and risk control of cold chain logistics of electricity supplier fresh products. Agro Food Ind HiTech 28(3):609-613

8. Davidaviciene V, Markus O, Davidavicius S (2020) Identification of the opportunities to improve customer's experience in e-commerce. J Log Inf Serv Sci 7(1):42-57

9. Dou X (2017) Status quo and countermeasures of the integration of cross-border agricultural e-commerce and cold chain logistics in China. Storage Process 17(4):134-138

10. Hu H, Djebarni R, Zhao X, Xiao L, Flynn B (2017) Effect of different food recall strategies on consumers' reaction to different recall norms: a comparative study. Ind Manag Data Syst 117(9):2045-2063

11. Luo L, Guo T, Zhang C, Xiao C, Wu L, He Y (2018) Dry deposition of atmospheric nitrogen in large reservoirs as drinking water sources: a case study from the danjiangkou reservoir, china. Environ Eng Manag J 17(9):2211-2219

12. Wang G (2018) Overview of supply chain transparent management in cold chain logistics of agricultural products. J Food Saf Qual 9(12):3212-3215

13. Gunasekaran A, Kobu B (2007) Performance measures and metrics in logistics and supply chain management: a review of recent literature (1995-2004) for research and applications. Int J Prod Res 45(12):2819-2840

14. Lim SFW, Xin J, Srai JS (2018) Consumer-driven e-commerce: a literature review, design framework, and research agenda on lastmile logistics models. Int J Phys Distrib Log Manag 48(3):308-332

15. Hu H, Wu Q, Zhang Z, Han S (2019) Effect of the manufacturer quality inspection policy on the supply chain decision-making and profits. Adv Prod Eng Manag 14(4):472-482

16. Zhang LL, Kim H (2020) The influence of financial service characteristics on use intention through customer satisfaction with mobile fintech. J Syst Manag Sci 10(2):82-94

17. Huseyinoglu IOY, Sorkun MF, Boruhan G (2018) Revealing the impact of operational logistics service quality on omni-channel capability. Asia Pac J Mark Log 30(5):1200-1221

18. Wu AH, Su JQ, Wang F (2014) A comprehensive evaluation of the logistics service quality based on vague sets theory. Int J Shipp Transp Log 6(1):69-87

19. Lalonde BJ, Zinszer PH (1976) Customer service: meaning and measurement. National Council of Physical Distribution Management, Chicago, pp 156-159

20. Mentzer JT, Gomes R, Krapfel RE (1989) Physical distribution service: a fundamental marketing concept. J Acad Mark Sci 17(1):53-62

21. Jun M, Cai SH (2010) Examining the relationships between internal service quality and its dimensions, and internal customer satisfaction. Total Qual Manag Bus Excell 21(2):205-223

22. Sohn JI, Woo SH, Kim TW (2017) Assessment of logistics service quality using the Kano model in a logistics-triadic relationship. Int J Log Manag 28(2):680-698

23. Parasuraman AP, Zeithaml VA, Berry LL (1994) Reassessment of expectations as a comparison standard in measuring service quality: implications for further research. J Mark 58(1):111-124

24. Bienstock CC, Mentzer JT, Bird MM (1997) Measuring physical distribution service quality. J Acad Mark Sci 25(1):31-44

25. Mentzer JT, Flint DJ, Hult TM (2001) logistics service quality as a segment-customized process. J Mark 65(4):82-104

26. Miao R, Cao JT, Zhang K, Chen BX, Jiang ZB, Wang LY (2014) Value-added path of service-oriented manufacturing based on structural equation model: the case of electric car rental for instance. Int J Prod Res 52(18):5502-5513
27. Kilibarda M, Nikolicic S, Andrejic M (2016) Measurement of logistics service quality in freight forwarding companies. Int $\mathrm{J}$ Shipp Transp Log 27(3):770-794

28. Gajewska T, Grigoroudis E (2017) Estimating the performance of the logistics services attributes influencing customer satisfaction in the field of refrigerated transport. Int J Shipp Transp Log 9(5):540-561

29. Hemalatha S, Dumpala L, Balakrishna B (2018) Service quality evaluation and ranking of container terminal operators through hybrid multi-criteria decision making methods. Asian J Shipp Log 34(2):137-144

30. Kong GL, Jiang LL, Yin XF, Wang TB, Xu DL, Yang JB, Hu YH (2018) Combining principal component analysis and the evidential reasoning approach for healthcare quality assessment. Ann Oper Res 271(2):679-699

31. Rajahonka M, Bask A (2016) The development of outbound logistics services in the automotive industry: a logistics service provider's view. Int J Log Manag 27(3):707-737

32. Wilson N, Hall T, Fields D (2011) Measuring retail service quality in farm supply cooperatives. Int Food Agribus Manag Rev 14(1):1-22

33. Wei X, Luo XF, Li Q, Zhang J, Xu Z (2015) Online commentbased hotel quality automatic assessment using improved fuzzy comprehensive evaluation and fuzzy cognitive map. IEEE Trans Fuzzy Syst 23(1):72-84

34. Mahtani US, Garg CP (2018) An analysis of key factors of financial distress in airline companies in India using fuzzy AHP framework. Transp Res Part A Policy Pract 117:87-102

35. Tuan L (2018) Promoting logistics performance in Vietnam-based manufacturing firms: the role of service-oriented high-performance work systems and mediation mechanisms. Int J Phys Distrib Log Manag. https://doi.org/10.1108/IJPDLM-07-2017-0238

36. Smith MH, Smith D (2018) Directing improvements in primary care patient experience through analysis of service quality. Health Serv Res 53(6):4647-4666

37. Segura-Garcia J, Felici-Castell S, Garcia-Pineda M (2018) Performance evaluation of different techniques to estimate subjective quality in live video streaming applications over LTE-Advance mobile networks. J Netw Comput Appl 107:22-37

38. Han SH, Cao B, Fu YF, Luo ZW (2017) A liner shipping competitive model with consideration of service quality management. Ann Oper Res 270(1-2):155-177

39. Ullah K, Mahmood T, Ali Z, Jan N (2020) On some distance measures of complex pythagorean fuzzy sets and their applications in pattern recognition. Complex Intell Syst 6(1):15-27

40. Miller F, Wang J, Zhu J, Chen Y, Hockenberry J (2017) Investigation of the impact of the Massachusetts health care reform on hospital costs and quality of care. Ann Oper Res 250(1):129-146

41. Roets B, Verschelde M, Christiaens J (2018) Multi-output efficiency and operational safety: an analysis of railway traffic control centre performance. Eur J Oper Res 271(1):224-237

42. Jia Z, Cai Y, Chen Y, Zeng WH (2018) Regionalization of water environmental carrying capacity for supporting the sustainable water resources management and development in China. Resour Conserv Recycl 134:282-293

43. Jin PJ, Wang EY, Huang N, Wang SH (2013) Catastrophe progression method on forecast of rock burst. Disaster Adv 6(7):34-38

44. Cheng X, Long RY, Chen H (2017) Obstacle diagnosis of green competition promotion: a case study of provinces in china based on catastrophe progression and fuzzy rough set methods. Environ Sci Pollut Res 25(5):4344-4360

45. Zhang Z, Wang L, Rodríguez MR, Wang YM, Luis M (2017) A hesitant group emergency decision making method based on prospect theory. Complex Intell Syst 3:177-187 
46. Tian $Y$, Wang H, Zhang X, Jin Y (2017) Effectiveness and efficiency of non-dominated sorting for evolutionary multi- and many-objective optimization. Complex Intell Syst 3(4):247-263

47. Wang LN, Chen XH, Xu YX, Huang MZ (2018) A catastrophe progression approach based index sensitivity analysis model for the multivariate flooding process. Stoch Environ Res Risk Assess 32(1):141-153

48. Pawlak Z (1982) Rough sets. Int J Comput Inform Sci 11(5):341-356
49. Perrault WD, Russ F (1974) Physical distribution service: a neglected aspect of marketing management. MSU Bus Top 22(6):37-45

Publisher's Note Springer Nature remains neutral with regard to jurisdictional claims in published maps and institutional affiliations. 